Original article

\title{
Learning and memory and its relationship with the lateralization of epileptic focus in subjects with temporal lobe epilepsy
}

\author{
Aprendizagem e memória e sua relação com a lateralização do foco epileptogênico em sujeitos com epilepsia do \\ lobo temporal
}

\author{
Daniel Fuentes 1,2, Leandro Fernandes Malloy-Diniz ${ }^{2,3}$, Clarice Gorenstein ${ }^{4,5}$, Blaise Christe 6,7, Geraldo F. Busatto 5,8
}

1 Psychology \& Neuropsychology Unit, Institute of Psychiatry, Clinical Hospital, Medical School, University of São Paulo (IPq-HCFMUSP).

2 Integrated Laboratories of Neuropsychology (LINEU), IPq-HCFMUSP.

${ }^{3}$ Department of Mental Health, School of Medicine, Universidade Federal de Minas Gerais (UFMG), Belo Horizonte.

${ }^{4}$ Department of Pharmacology, Institute of Biomedical Sciences, USP; Laboratory of PSychopharmacology - LIM-23, IPq-HCFMUSP.

${ }_{5}^{5}$ Center for Interdisciplinary Research on Applied Neurosciences (NAPNA), USP.

${ }^{6}$ Neuropsychology Unit, Department of Neurology, Geneva University Hospitals and Medical School, Switzerland.

${ }^{7}$ Neurology Outpatients' Clinic, Department of Neurology, Geneva University Hospitals and Medical School, Switzerland.

${ }^{8}$ Department of Psychiatry, HCFMUSP.

Received: 1/31/2014 - Accepted: 2/5/2014

\begin{abstract}
Background: In medial temporal lobe epilepsy (MTLE), previous studies addressing the hemispheric laterality of epileptogenic focus and its relationship with learning and memory processes have reported controversial findings. Objective: To compare the performance of MTLE patients according to the location of the epileptogenic focus on the left (MTLEL) or right temporal lobe (MTLER) on tasks of episodic learning and memory for verbal and visual content. Methods: One hundred patients with MTLEL and one hundred patients with MTLER were tested with the following tasks: the Rey Auditory Verbal Learning Test (RAVLT) and the Logical Memory-WMS-R to evaluate verbal learning and memory; and the Rey Visual Design Learning Test (RVDLT) and the Visual Reproduction-WMS-R to evaluate visual learning and memory. Results: The MTLEL sample showed significantly worse performance on the RAVLT $(p<0.005)$ and on the Logical Memory tests $(\mathrm{p}<0.01)$ than MTLER subjects. However, there were no significant between-group differences in regard to the visual memory tests. Discussion: Our findings suggest that verbal learning and memory abilities are dependent on the structural and functional integrity of the left temporal lobe, while visual abilities are less dependent on the right temporal lobe.
\end{abstract}

Fuentes D, et al. / Rev Psiq Clín. 2014;41(1):1-4

Keywords: Memory, learning, neurocognitive test, neuropsychology, epilepsy, temporal lobe.

\section{Resumo}

Contexto: Estudos anteriores abordando a lateralidade hemisférica de foco epiléptico na epilepsia do lobo temporal mesial (ELTM) e sua relação com os processos de aprendizagem e memória têm relatado resultados controversos. Objetivo: Comparar o desempenho de pacientes com ELTM de acordo com a localização do foco epiléptico à esquerda (ELTME) ou à direita (ELTMD) em tarefas de aprendizagem e memória episódica para conteúdo verbal e visual. Métodos: Cem pacientes com ELTME e cem pacientes com ELTMD foram avaliados com os seguintes testes: Teste de Aprendizagem Auditiva Verbal de Rey (RAVLT) e Memória Lógica - WMS-R para avaliar aprendizagem e memória verbal e o Teste de Aprendizagem Visual para Desenhos de Rey (RVDLT) e Reprodução Visual - WMS-R para avaliar a aprendizagem e memória visual. Resultados: A amostra com ELTME mostrou desempenho significativamente pior no RAVLT $(\mathrm{p}<0,005)$ e na Memória Lógica $(\mathrm{p}<0,01)$ em comparação aos indivíduos ELTMD. No entanto, não houve diferenças significativas entre os grupos no que diz respeito aos testes de aprendizagem e memória visual. Conclusão: Nossos resultados sugerem que a aprendizagem e a memória verbais são dependentes da integridade estrutural e funcional do lobo temporal esquerdo, enquanto as capacidades de aprendizagem e memória visual são menos dependentes do lobo temporal direito.

Fuentes D, et al. / Rev Psiq Clín. 2014;41(1):1-4

Palavras-chave: Memória, aprendizagem, teste neurocognitivo, neuropsicologia, epilepsia, lobo temporal.

\section{Introduction}

Medial temporal lobe epilepsy (MTLE) is the most frequent epileptogenic disorder ${ }^{1}$. In MTLE, the primary brain network involved includes structures of the limbic system, mainly the hippocampus and amygdala that are crucially implicated in learning and memory processes. Epileptogenic foci are most often localized in one brain hemisphere, although epileptogenic medial temporal lesions are bilateral in many cases ${ }^{1,2}$. Neuropsychological assessment of MTLE patients is important to document cognitive impairments in specific domains, such as episodic memory $y^{3,4}$ and linguistic and nonlinguistic functions ${ }^{5,6}$. The brain location of the epileptogenic focus in MTLE is determinant to the kind of cognitive impairment presented by each patient. However, previous studies addressing the hemispheric laterality of epileptogenic focus and its relationship with learning and memory processes have been controversial.

As early as in the 1950s, Brenda Milner argued that MTLE with unilateral epileptogenic focus located on the left hemisphere (MTLEL) leads to episodic learning and memory verbal deficits, while MTLE with focus on the right hemisphere (MTLER) would lead to visual impairments on learning and memory ${ }^{7-9}$. In consistency with that proposition, Jones-Gotman ${ }^{10}$ found that patients with lesions in the right temporal lobe presented more impairments on episodic learning and memory for visual content, while patients with left temporal lobe lesions presented more impairments on learning and memory for verbal content. 
Several authors, however, found no learning and memory deficits in MTLE patients with unilateral lesions located on the right hemisphere, although confirming the existence of episodic learning and memory deficits for verbal content in MTLE affecting the left hemisphere ${ }^{11-15}$.

In contrast, Glowinski16 found that patients with unilateral epileptogenic focus, regardless of the hemisphere affected, presented worse performance on verbal memory tasks compared with healthy controls. Finally, Vingerhoets et al. ${ }^{17}$ comparing the cognitive performance of subjects with MTLER and MTLEL during the intracarotid amobarbital test and found that MTLER patients performed worse than MTLEL subjects on tasks using verbal stimuli. No difference between groups was found in the memory and learning tasks using visual material.

The controversies above allow the formulation of at least two conflicting hypotheses about the organization of the processes of episodic memory (encoding, storage and retrieval) for verbal and visual information. The first hypothesis, that we called doubleconcordance hypothesis, is that verbal information processing is related to the temporal lobe of the left hemisphere, while learning and memory processing of visual information would be dependent of the right temporal lobe. The second proposition, that we denominated simple-concordance hypothesis, is that learning and memory for verbal information depends on the left temporal lobe, but the same is not true for the relationship between visual memory and the right temporal lobe.

The aim of the present study was to compare the performance of MTLE patients according to the location of the epileptogenic focus on the right or left temporal lobe on tasks of episodic learning and memory for verbal and visual content.

\section{Methods}

\section{Participants}

We assessed 200 epileptic patients divided in two groups: 100 with the epileptic focus on left temporal lobe (48 males and 52 females), and 100 on the right temporal lobe ( 51 males and 49 females), as assessed by high-resolution magnetic resonance imaging scans visually interpreted by experienced radiologists. Patients were referred by clinicians of the Institute of Psychiatry at the University of São Paulo, and they were assessed between the years of 1998 and 2013 at the Neuropsychology and Psychology Unit of the same institution. The age of the subjects ranged from 18 to 70 years. All subjects had unilateral epileptic focus (left or right) according to the criteria of the International League Against Epilepsy (ILAE) ${ }^{18}$. Subjects who presented symptoms of any comorbid neuropsychiatric disorders, as diagnosed by their treating clinicians, were excluded from the present investigation. Patients gave their informed signed consent to participate in the research and the local Ethical Committee approved the study.

\section{Procedures}

All subjects underwent testing with a neuropsychological battery including the following tasks that assessed verbal or visual episodic learning and memory.

\section{Rey Auditory Verbal Learning Test (RAVLT/19,20}

In the RAVLT, a list of 15 substantives (list A) is read aloud to the subject five consecutive times. Each of the attempts is followed by a test of spontaneous retrieval. After the fifth attempt, a list of interference, also comprising 15 substantives (list B) is read to the subject, followed by its retrieval (attempt B1). After attempt B1, the examiner asks the individual to recall the words from list $A$, without reading it again (attempt A6). In order to evaluate the learning curve of the words during attempts A1 to A5, the rate of learning during the attempts - LOT was employed, calculated with the following formula: total sum of A1 to A5 - (5 x A1). After a 30-minute interval, the examiner asks the individual to remember the words from list A (attempt A7) without reading this list. After attempt A7, the individual is submitted to a test of memory recognition, in which a list comprising the 15 words from list $\mathrm{A}$, the 15 words from list $\mathrm{B}$, as well as 20 distracting words (similar to the words in list A and B in phonological or semantic terms) is read to the individual. In the present study, we used only the measures of learning and memory of the RAVLT: first retrieval of list A (A1), LOT, retrieval after 30 minutes, and recognition memory.

\section{Rey Visual Desing Learning Test (RVDLT)19}

The RVDLT is the visual counterpart of the RAVLT. In this test, 15 simple designs are shown to the subject five consecutive times. Each of the attempts is followed by a test of spontaneous retrieval, where the subjects have to reproduce the designs that they are able to remember. There is not interference list on this test. In order to evaluate the learning curve of the words during attempts A1 to A5, we calculated learning scores during the attempts - LOT with the same formula used on the RAVLT. After a 30-minute interval, the examiner asks the individual to remember and reproduce the designs without showing them to the subject. After this attempt, the individual is submitted to a test of memory recognition, in which a list comprising the 15 designs and other distracting designs is shown to the individual. In the present study, we used only the measures of learning and memory of the RVDLT: first retrieval of list A (A1), LOT, retrieval after 30 minutes, and recognition memory.

\section{Rey-Osterrieth Complex Figure Test (ROCFT)19}

In this task, subjects had to copy a complex non-structured figure as similar as possible to the model. After three minutes, he/she had to reproduce the figure from memory as similar as possible to the model. The reproduction from memory was scored according to a standard version of the 36-point scoring system.

\section{Visual reproduction test of the Wechsler Memory Scale ${ }^{21}$}

Both immediate memory and long-term memory for visual content are assessed on this test.

The VRT is composed of four cards, three of which contain a single geometric figure on separated cards. The fourth card presents two geometric figures. The individual is asked to observe each card for 10 seconds, and afterwards then draw it from memory (immediate recall). Thirty minutes later, the individual are asked to draw the figures again (delayed recall).

\section{Logical Memory Test (LMT)21}

The LMT is a standardized test widely used as a clinical assessment measure of verbal memory. Requiring the immediate and delayed recall of two short stories (three-sentence verbal narrative), each consisting of 24 bits of information. The two stories are auditorally presented sequentially in the immediate recall condition, and free recall of the story is elicited after each presentation. Thirty minutes later, free recall of the two stories is again elicited.

\section{Intelligence assessment}

The vocabulary and cubes subtests of the Wechsler Adult Intelligence Scale ${ }^{22}$ were used in order to estimate subject's Intelligence Quoficient.

\section{Statistical analyses}

Comparison between groups was performed using Student's t-tests for independent samples. In this analysis the level of significance was $\mathrm{p}<0.05$. 


\section{Results}

Demographic characteristics and neuropsychological performance of both groups are provided in table 1. Both the MTLER and MTLEL groups were similar in regard to intelligence, gender distribution, years of formal education and age (Table 1).

MTLEL patients performed worse than MTLER on almost all items assessed on verbal tests (Table 1). There was no difference between the two groups only on the A1 trial of the RAVLT. No differences were found between the MTLER and MTLEL groups in regard to visual tests of learning and memory (Table 1 ).

\section{Discussion}

In this large sample of patients with unilateral MTLE, patients with MTLEL presented worse performance on verbal episodic learning and memory tasks compared with those subjects with MTLER. In only one measure of verbal memory (the A1 trial of RAVLT), there was no significant difference between the two groups. Such lack of difference could be explained by the fact that the first retrieval of the word list is more dependent on short-term memory rather than on long-term, episodic memory. This short-term ability is related to working memory, which is highly reliant on the integrity of the dorsolateral prefrontal cortex ${ }^{23}$. Since the brain lesions of MTLE subjects are located in the temporal lobe, such lack of between-group differences could be interpreted as a result of the integrity of functioning of other, frontal-lobe centered circuits in MTLE patients.

Considering visual memory and learning tests, no significant differences were found between groups. From the two hypothesis that we have put forward in the present article, our findings are in agreement with the second one (ie. simple-concordance), suggesting that verbal abilities are dependent on the structural and functional integrity of the left temporal lobe, while visual abilities would be less dependent on right temporal lobe regions.

According to Vannucci ${ }^{24}$, there are two types of episodic visual memory tasks: one that is related to reproduction of geometric figures (e.g. ROCFT and Visual Reproduction Subtest of WMS), and one other that involves figural learning over trails, with recall after an interval and recognition memory (e.g. RVDLT). It has been proposed that this second group of tasks would be more sensitive to impaired functioning of the right temporal lobe than the first group, and several studies have presented evidence of such material-specific deficits for visual stimuli linked to the right temporal lobe using these tasks $\mathbf{s}^{10,25,26}$. However, in the present study we used both figural reproduction and figural learning tests, and we did not find any significant differences between MTLER and MTLEL patients using either of those tasks.

One limitation of the present study is that we did not assess hemispheric language dominance in MTLE subjects. Kim et al. ${ }^{26}$ reported material-specific memory impairment in association with MTLE considering not only the side of lesion but also hemispheric language dominance. They found that MTLEL patients with left hemisphere language dominance showed significantly higher nonverbal than verbal memory capacity, whereas MTLER patients with left hemisphere language dominance showed significantly better verbal than nonverbal memory capacity. MTLEL patients with non-left-hemisphere language dominance showed significantly better verbal memory capacity compared with MTLEL patients with left-hemisphere language dominance. The authors interpreted these results as suggesting that selective verbal or nonverbal memory deficits are dependent both on the side of seizure onset and the hemispheric language dominance.

There are other limitations that warrant caution in the interpretation of the present findings, such as the absence of a healthy control group and the lack of structured diagnostic interviewing to rule out psychiatric comorbidities. Also, we did not evaluate the relationship between memory deficits and the doses and usage length of anticonvulsant drugs, which are known to affect cognitive performance in MTLE patients ${ }^{27}$.

The systematic investigation of brain lesions or specific dysfunctions has been crucial to the development of the Science of Neuropsychology, fomenting with empirical data the different theoretical proposals about brain-behavior-cognition relationships. As shown by the present study, it remains useful to carry out studies of clinical populations to increase understanding about the relationship between neural networks and cognitive systems in healthy human beings. Our data highlights that there is much yet to be clarified in regard to the brain substrate for episodic learning and memory processes. Future investigations in this field of knowledge have to consider both lateralization of epileptic focus and factors such as use of medication, duration of disease, and hemispheric language dominance.

Table 1. Demographic details and comparison of the performance of medial temporal lobe epilepsy patients on neuropsychological tests of learning and memory

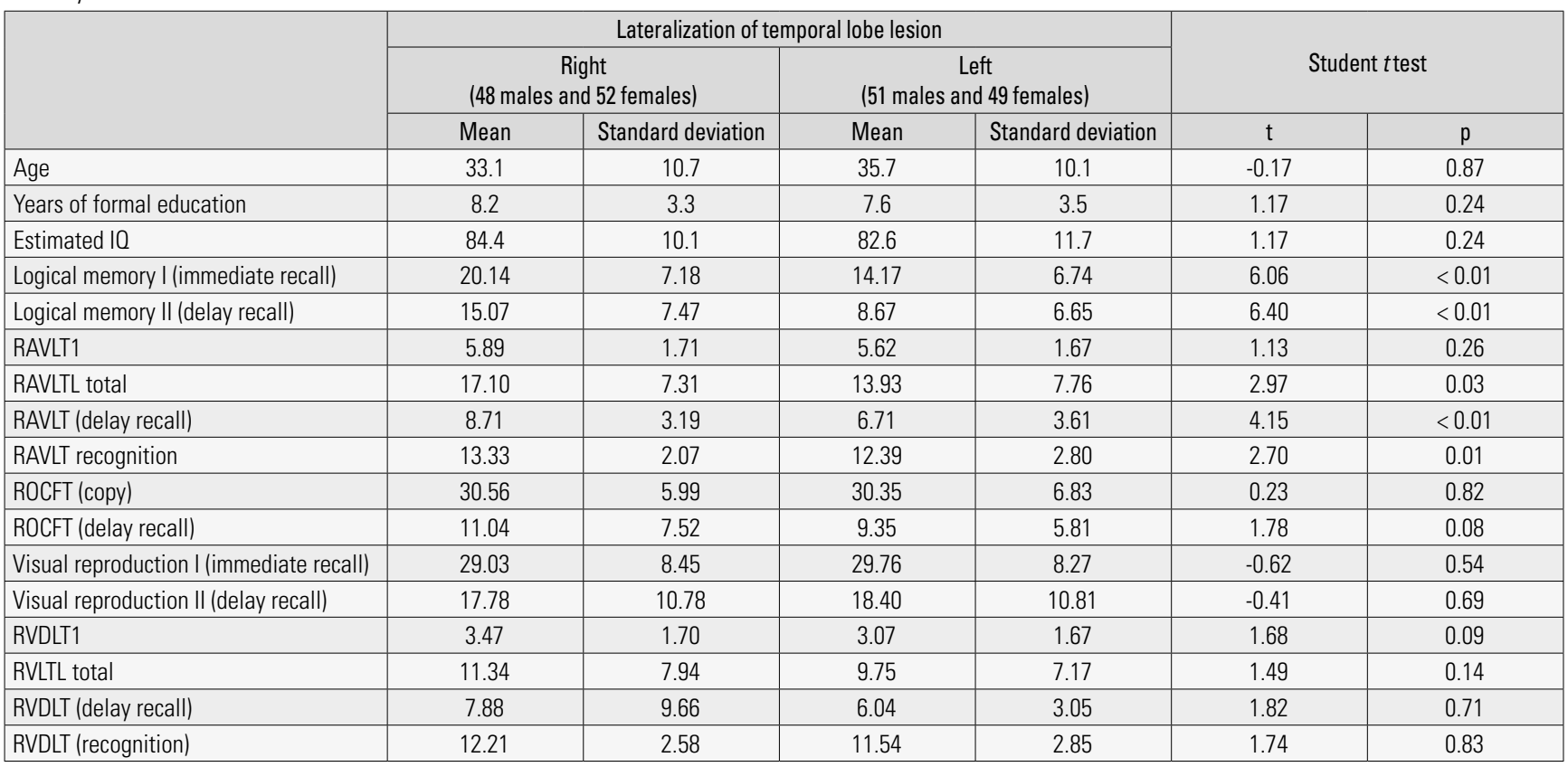

IQ: Intelligence Quoficient; RAVLT: Rey Auditory Verbal Learning Test; ROCFT: Rey-Osterrieth Complex figure; RVDLT: Rey Visual Desing Learning Test. 


\section{Acknowledgements}

Clarice Gorenstein and Geraldo F. Busatto are partially funded by $\mathrm{CNPq}$ (Brazil). We thank Kette D. Valente for helpful comments on preliminary presentations of the present data in medical conferences.

\section{References}

1. Engel J. Introduction to temporal lobe epilepsy. Epilepsy Res. 1996;26(1):141-50

2. Gois J, Valente K, Vicentiis S, Moschetta S, Kuczynski E, Fiore L, et al. Assessment of psychosocial adjustment in patients with temporal lobe epilepsy using a standard measure. Epilepsy Behav. 2011;20(1):89-94.

3. Leritz EC, Grande LJ, Bauer RM. Temporal lobe epilepsy as a model to understand human memory: the distinction between explicit and implicit memory. Epilepsy Behav. 2006;9(1):1-13.

4. Rzezak P, Guimarães C, Fuentes D, Guerreiro MM, Valente KD. Episodic and semantic memory in children with mesial temporal sclerosis. Epilepsy Behav. 2011;21(3):242-7.

5. Perrine K, Uysal S, Dogali M, Luciano DJ, Devinsky O. Functional mapping of memory and other nonlinguistic cognitive abilities in adults. Adv Neurol. 1993;63:165-77.

6. Guimarães CA, Li LM, Rzezak P, Fuentes D, Franzon RC, Augusta Montenegro $\mathrm{M}$, et al. Temporal lobe epilepsy in childhood: comprehensive neuropsychological assessment. J Child Neurol. 2007;22(7):836-40.

7. Milner B. Psychological defects produced by temporal lobe excision. Res Publ Assoc Res Nerv Ment Dis. 1958;36:244-57.

8. Milner B. Visual recognition and recall after right temporal excision in man. Neuropsychologia. 1968;6:191-209.

9. Milner B. Psychological aspects of focal epilepsy and its neurosurgical management. Adv Neurol. 1975;8:299-321.

10. Jones-Gotman M, Zatorre RJ, Olivier A, Andermann F, Cendes F, Staunton $\mathrm{H}$, et al. Learning and retention of words and designs following excision from medial or lateral temporal-lobe structures. Neuropsychologia. 1997;5:963-73.

11. Bornstein RA, Pakalnis A, Drake ME Jr, Suga LJ. Effects of seizure type and waveform abnormality on memory and attention. Arch Neurol. 1988;45(8):884-7.

12. Cohen M. Auditory/verbal and visual/spatial memory in children with complex partial epilepsy of temporal lobe origin. Brain Cogn. 1992;20(2):315-26
13. Giovagnoli AR, Avanzini G. Learning and memory impairment in patients with temporal lobe epilepsy: relation to the presence, type, and location of brain lesion. Epilepsia. 1999;40(7):904-11.

14. Moore PM, Baker GA. Validation of the Wechsler Memory Scale-Revised in a sample of people with intractable temporal lobe epilepsy. Epilepsia. 1996;37(12):1215-20.

15. Selwa LM, Berent S, Giordani B, Henry TR, Buchtel HA, Ross DA. Serial cognitive testing in temporal lobe epilepsy: longitudinal changes with medical and surgical therapies. Epilepsia. 1994;35(4):743-9.

16. Glowinski H. Cognitive deficits in temporal lobe epilepsy. An investigation of memory functioning. J Nerv Ment Dis. 1973;157(2):129-37.

17. Vingerhoets G, Miatton M, Vonck K, Seurinck R, Boon P. Memory performance during the intracarotid amobarbital procedure and neuropsychological assessment in medial temporal lobe epilepsy: the limits of material specificity. Epilepsy Behav. 2006;8(2):422-8.

18. International League Against Epilepsy (ILAE). The history and stigma of epilepsy. Epilepsia. 2003;44:12-4

19. Strauss E, Sherman EMS, Spreen O, Spreen O. A compendium of neuropsychological tests: administration, norms, and commentary. Oxford: Oxford University Press; 2006.

20. Salgado JV, Malloy-Diniz LF, Abrantes SS, Moreira L, Schlottfeldt CG, Guimarães W, et al. Applicability of the Rey auditory-verbal learning test to an adult sample in Brazil. Rev Bras Psiquiatr. 2011;33(3):234-7.

21. Wechesler D. WMS-R: administration and scoring manual. San Antonio: The Psychological Corporation; 1997.

22. Wechesler D. WAIS-R: administration and scoring manual. San Antonio: The Psychological Corporation; 1981.

23. Malloy-Diniz LF, De Paula JJ, Sedó M, Fuentes D, Leite WB. Neuropsicologia das funções executivas e da atenção. In: Fuentes D, Malloy-Diniz LF, Camargo CHP, Cosenza R, editors. Neuropsicologia: teoria e prática. 2nd edition. Porto Alegre: Artmed; 2014. p. 115-38.

24. Vannucci M. Visual memory deficits in temporal lobe epilepsy: toward a multifactorial approach. Clin EEG Neurosci. 2007;38(1):18-24.

25. Jones-Gotman M. Right hippocampal excision impairs learning and recall of a list of abstract designs. Neuropsychologia. 1986;24(5):659-70.

26. Kim H, Sangdoe Y, Eun IS, Jieun K. Material-specific memory in temporal lobe epilepsy: effects of seizure laterality and language dominance. Neuropsychology. 2003;17:59-68.

27. Perry MS, Duchowny M. Surgical versus medical treatment for refractory epilepsy: outcomes beyond seizure control. Epilepsia. 2013;54(12):2060-70. 